\title{
Pesticides residue analysis in yam from selected markets across Ghana and Belgium: an evaluation of the QUECHERS method
}

\author{
Abukari Wumbei ${ }^{1,2^{*}}$ (D), David Senaeve ${ }^{1}$, Michael Houbraken ${ }^{1}$ and Pieter Spanoghe ${ }^{1}$
}

\begin{abstract}
Background: In recent years, concerns have been raised in Ghana regarding the use of pesticides in yamproduction to the extent that it is feared that pesticides residues may be found in the yam tuber which isconsumed by many Ghanaians. This present study, therefore, was designed to assess the level of pesticides residues in yam bought from across Ghanaian markets i.e. production for local consumption and from Belgium grocery shops (export production from Ghana) using the Quick, Easy, Cheap, Efficient, Rugged and Safe (QuEChERS) method coupled with LC-MS/MS. A total of 180 yam samples, including 150 from Ghana and 30 from Belgium were collected and pesticides residues were analyzed using a multi-residue method.

Results: A total of 25 pesticides were screened in the yam samples and 11 of them were detected. Theresults indicated that about $46 \%$ of the samples contained one or more of the 11 detected pesticides in arange of 0 . $000014 \mathrm{mg} / \mathrm{kg}$ up to $0.0146 \mathrm{mg} / \mathrm{kg}$. The three most detected pesticides in this study were fenpropimorph, cadusafos and fenitrothion, occurring in 179, 171 and 126 samples respectively. All the detected pesticides were below their respective EU maximum residue limits (MRL).

Conclusion: By these results, it can be said that, the residues of the monitored pesticides found in yam arevery low and are unlikely to pose a negative human health effect.
\end{abstract}

Keywords: Pesticides, Residues, Yam, Ghana, Human health. Maximum residue limit (MRL)

\section{Background}

The effort of the global community over the years at producing enough food to meet the demand for food that has tripled over the last 50 years (Bodirsky et al. 2015) has brought about new incentives and policies in agriculture. Key among the new incentives is the gross liberalization of the pesticides trade in both developed and developing countries to make pesticides affordable and accessible to famers. Because of these policy shifts, farmers who hitherto did not use pesticides, now use them and certain sectors of national agriculture which in the past were not known to be associated with

\footnotetext{
* Correspondence: awumbe2003@yahoo.com; abukari.wumbei@ugent.be 'Department of Crop Protection Chemistry, Faculty of Bioscience Engineering, Ghent University, Ghent, Belgium

${ }^{2}$ Institute for Interdisciplinary Research and Consultancy, University for Development Studies Services, P. O. Box TL 1350, Tamale, Ghana
}

pesticides, now use pesticides. A typical example is the case of Ghana where in the past pesticides use was restricted to a few crops such as cocoa in southern Ghana, cotton in northern Ghana and fruits and vegetables in both southern and northern Ghana, which has been extended to many other areas today (Ntow et al. 2009) including the production of yam.

Yam is a major food crop grown in many regions of Ghana and usually by small holder farmers (Anaadumba 2013). A few decades ago, the crop was cultivated using rudimentary practices, but today farmers use modern farming technologies including herbicides due to several factors. These factors include 'in particular' the commercialization of farming, dwindling labour force in the yam production areas and increasing weed pressure due to climate variability and overcultivation of the soil. 
The main herbicides used by the yam farmers are glyphosate and atrazine. Although, the farmers maintain the believe that the use of the pesticides help them to increase their production, there is public concern about the human health impacts of these products as there could be residues of the products in the yam that they consume (Cha et al. 2014). Of the numerous studies that have been conducted in Ghana on pesticides residues in food commodities (Asiedu 2013; Bempah and Donkor 2011) no study has yet been carried out on yam. Indeed, the study of Adeyeye and Osibanjo (1999) in Nigeria found residues of aldrin, dieldrin and DDT in yam, but not any herbicide. The present study therefore, was designed to investigate the hypothesis that there are pesticides residues in yam produced in Ghana with the objectives: (1) to conduct multiple pesticides residue analysis (LC-MS/MS) in yam from Ghanaian markets (local production) and from Belgian shops (export production) using the Quick, Easy, Cheap, Efficient, Rugged and Safe (QuEChERS) method and (2) to compare residue levels with the acceptable international food safety limits (MRL).

\section{Methods}

\section{Sampling}

A total of 180 yam samples were collected. Out of this number, 150 samples were collected in Ghana and 30 samples were collected in Belgium.

\section{Sampling and sample preparation in Ghana}

The Ghana samples were collected from five regions and from eight markets. During the sampling, samples were collected from one market each in the Northern region and Brong Ahafo region and from two markets each from the Ashanti, Greater Accra and Western regions. These markets (Fig. 1) include: Aboabu Central Market in Tamale (Northern region), Kintampo Yam Market (Brong Ahafo region), Moro Market and Ejisu Market in Kumasi (Ashanti region), Anaji Market and Market Centre in Takoradi (Western region) and Ashaiman Market and Konkomba Market (Greater Accra region). Sampling was done every week for six weeks between June and July 2016. A total of 30 samples were collected per regional market over the six-week period. During sampling yam retailers were interviewed about the

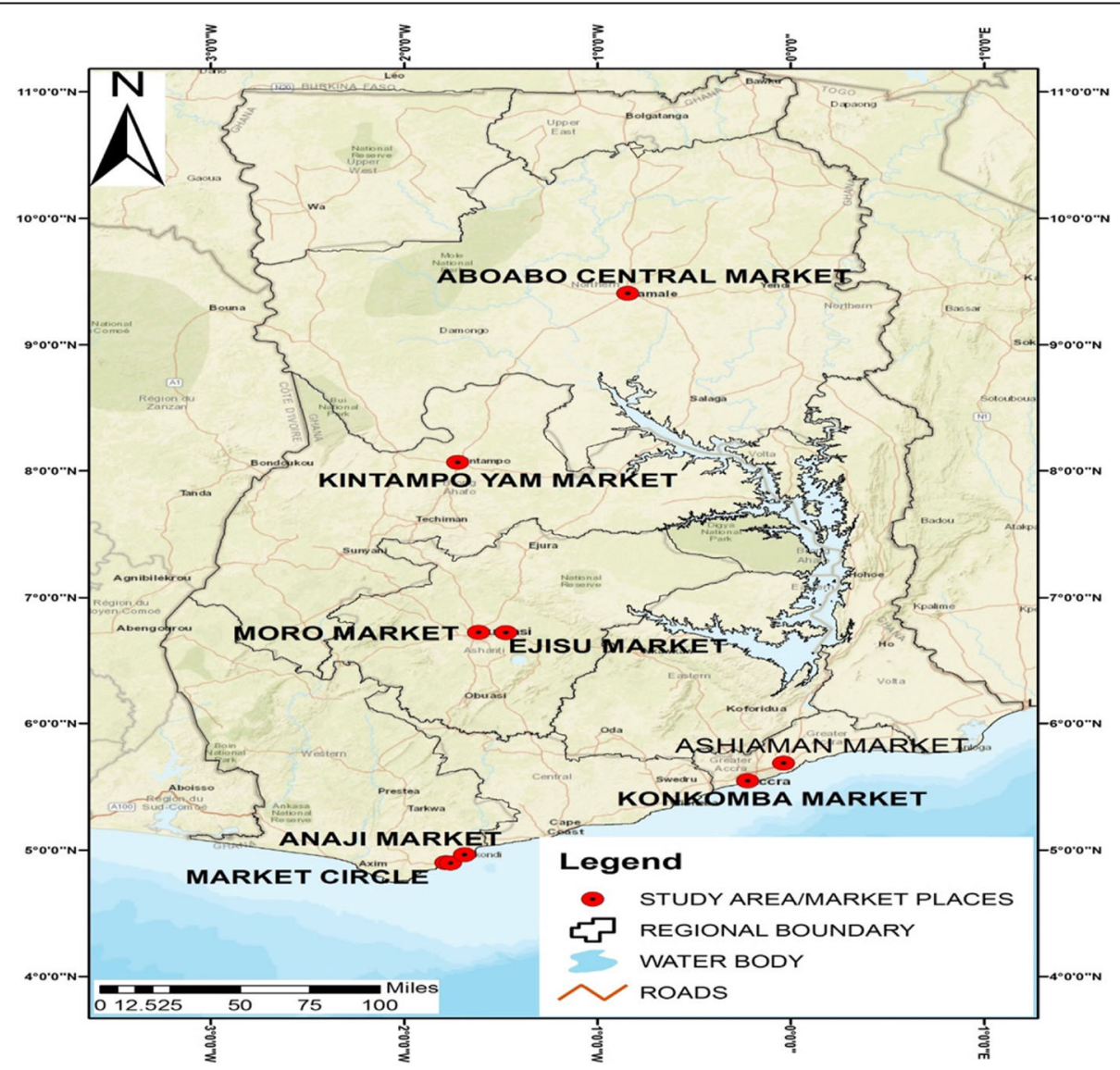

Fig. 1 Study area of the Ghana yam market survey (Alex Owusu, University of Ghana) 
source of the yam they sell. The retailers indicated that they bought the yam from bulk sellers in the market who have the financial opportunity to go to the hinterlands with big trucks to buy yam directly from farmers and from local retailers. From this, it was realized that yam sold in the city markets are not originating from one source, but from multiple sources. After sampling, $50 \mathrm{~g}$ of each sample was ground using a blender. After blending of each sample the blender was cleaned thoroughly to prevent cross contamination. The blended yam was filled into $50 \mathrm{ml}$ laboratory tubes, each of which was cupped, wrapped with a cello tape and kept into a transparent rubber bag. At this stage samples from each market were neatly wrapped into a larger and stronger rubber bag and frozen before being transported to the laboratory of Crop Protection Chemistry at Ghent University, Belgium. From there it was stored at $-20{ }^{\circ} \mathrm{C}$ until extraction and analysis.

\section{Sampling and sample preparation in Belgium}

The Belgium samples were collected from five shops spread across the city of Ghent in Belgium. These shops include; Jazwal Enterprise, Foreign Shop, Asian/African Shop, Africa/Caribbean Shop and Special Exotic Shop. Sampling in Belgium, like in Ghana was done within six weeks, but between January and February 2017. During the six weeks, one sample was collected from each of the five selected shops. During sampling, the shop owners were interviewed about the countries from which the yam they sold came from. The countries from which these shop owners imported yam include: Ghana, Cameroon and Nigeria. However, during the sampling period all the yams in the shops sampled were from Ghana. The samples were processed in a similar manner like those in Ghana, but without cello tapes and further wrapping. They were stored in a freezer at $-20{ }^{\circ} \mathrm{C}$ until extraction and analysis.

\section{Reagents and materials}

Laboratory reagents of high purity were used. Acetonitrile (analytical grade) was obtained from VWR PRO-LABO Suppliers and high-performance liquid chromatography
(HPLC) grade water and acetone were supplied by ALLtech. Analytical grade salts (Table 1) including; magnesium sulfate anhydrous ( $\mathrm{MgSO} 4)$, sodium citrate tribasic dihydrate $\left(\mathrm{C}_{6} \mathrm{H}_{2} \mathrm{Na}_{3} \mathrm{O}_{7} 2 \mathrm{H}_{2} \mathrm{O}\right)$, sodium hydrogen citrate sesquihydrate $\left(\mathrm{C}_{6} \mathrm{H}_{6} \mathrm{Na}_{2} \mathrm{O}_{7} 1.5 \mathrm{H}_{2} \mathrm{O}\right)$ and sodium chloride $(\mathrm{NaCl})$ to remove remaining water in organic solvents were supplied by Thermo Fisher Scientific Suppliers. Polypropylene centrifuge tubes $(50 \mathrm{~mL})$ were obtained from Thermo Fisher Scientific Suppliers.

\section{Pesticides analytical standards}

Pesticides analytical standards (Table 2) which were used in recovery experiments to validate the QuEChERS method on yam, were supplied by Supelco and delivered by Sigma-Aldrich Logistics. Before settling on these pesticides, a list of pesticides from the Ghana updated pesticides register was made. These were common pesticides on the Ghanaian market with the potential to be used on yam. However, after an initial assessment of the analytical equipment (Waters ACQUITY UPLC, Xevo TQD mass spectrometer) on the 82 pesticides on raw yam samples, it was observed that some of the pesticides could not be handled by LC-MS/MS in one analytical run with a high sensitivity and appropriate recovery, hence the list was reduced to 25 .

\section{Analytical equipment}

Chromatographic separation of analytes was done by LC-MS/MS analysis on a triple quadrupole system with ESI (Waters ACQUITY UPLC, Xevo TQD mass spectrometer). Conditions and parameters of the analytical equipment are provided in Table 3.

\section{Analytical method validation}

The analytical procedure based on the QuEChERS method was validated for yam before being used in this study. In the validation process, the limit of detection (LOD) and the limit of quantification (LOQ) were determined by preparing matrix spikes at a low level near the expected detection limit. In this study, a uniform volume of $100 \mu \mathrm{L}(0.0007 \mathrm{mg} / \mathrm{L})$ for all the pesticides (Table 2) was spiked into the yam in eight

Table 1 Reagents and Materials and their respective analytical purities

\begin{tabular}{llll}
\hline No & Reagent & Purity (\%) & Suppliers \\
\hline 1 & Acetonitrile & 99.9 & WWR PRO-LABO \\
2 & Acetone & 99.0 & ALLtech \\
3 & Water (Milli Q) & 100.0 & ALLtech \\
4 & Magnesium sulfate anhydrous (MgSo4) & 99.5 & Thermo Fisher \\
5 & Sodium chloride (NaCl) & 99.0 & Thermo Fisher \\
6 & Sodiumcitratetribasic dihydrate $\left(\mathrm{C}_{6} \mathrm{H}_{2} \mathrm{Na}_{3} \mathrm{O}_{7} 2 \mathrm{H}_{2} \mathrm{O}\right)$ & 99.0 & Thermo Fisher \\
7 & Sodiumhydrogencitrate sesquihydrate $\left(\mathrm{C}_{6} \mathrm{H}_{6} \mathrm{Na}_{2} \mathrm{O}_{7} 1.5 \mathrm{H}_{2} \mathrm{O}\right)$ & 99.0 & Thermo Fisher \\
\hline
\end{tabular}


Table 2 Pesticides Analytical Standards (suppliers, Sigma-Aldrich and purity, 99\%)

\begin{tabular}{|c|c|c|c|c|c|c|c|}
\hline \multirow[t]{2}{*}{ No } & \multirow{2}{*}{$\begin{array}{l}\text { Pesticide } \\
\text { analytical } \\
\text { standard }\end{array}$} & \multicolumn{6}{|c|}{ LC-MS/MS Conditions for Analysis } \\
\hline & & Parent & $C V(V)$ & Product 1 & CE (eV) & Product 2 & CE $(e V)$ \\
\hline 1 & acetamiprid & 222.0 & 28 & 126.0 & 20 & 56.1 & 15 \\
\hline 2 & azoxystrobin & 404.0 & 22 & 372.0 & 15 & 329.0 & 30 \\
\hline 3 & bentazone & 241.1 & 15 & 199.1 & 12 & 107.2 & 26 \\
\hline 4 & butachlor & 312.2 & 20 & 57.3 & 22 & 238.2 & 12 \\
\hline 5 & cadusafos & 271.1 & 22 & 159.0 & 16 & 131.0 & 22 \\
\hline 6 & carbendazim & 192.1 & 27 & 160.1 & 18 & 132.1 & 28 \\
\hline 7 & carbofuran & 222.1 & 28 & 165.1 & 16 & 123.0 & 16 \\
\hline 8 & chlorpyriphos & 349.9 & 30 & 97.0 & 32 & 198.0 & 20 \\
\hline 9 & difenconazole & 406.0 & 40 & 251.1 & 25 & 111.1 & 60 \\
\hline 10 & diuron & 233.0 & 28 & 72.1 & 18 & 46.3 & 14 \\
\hline 11 & dimethoate & 230.1 & 18 & 125.0 & 20 & 199.0 & 10 \\
\hline 12 & diazinon & 305.1 & 25 & 169.0 & 22 & 96.9 & 35 \\
\hline 13 & epoxiconazole & 330.0 & 28 & 121.0 & 22 & 106.0 & 32 \\
\hline 14 & fenitrothion & 278.0 & 32 & 109.1 & 20 & 79.1 & 32 \\
\hline 15 & fenpropimorph & 304.2 & 44 & 147.1 & 28 & 57.2 & 30 \\
\hline 16 & imidacloprid & 256.1 & 28 & 175.1 & 20 & 209.1 & 15 \\
\hline 17 & malathion & 331.0 & 14 & 127.0 & 12 & 99.0 & 24 \\
\hline 18 & metalaxyl & 280.1 & 20 & 220.1 & 13 & 192.1 & 17 \\
\hline 19 & pendimethalin & 282.2 & 15 & 212.2 & 10 & 194.1 & 17 \\
\hline 20 & profenofos & 372.9 & 30 & 302.6 & 20 & 127.9 & 40 \\
\hline 21 & propanil & 217.9 & 34 & 161.9 & 16 & 127.0 & 22 \\
\hline 22 & propiconalzole & 344.0 & 16 & 326.0 & 12 & 189.0 & 20 \\
\hline 23 & propoxur & 210.0 & 15 & 111.0 & 16 & 168.0 & 10 \\
\hline 24 & pyraclostrobin & 388.1 & 25 & 163.0 & 25 & 193.9 & 12 \\
\hline 25 & tryfloxystrobin & 409.0 & 28 & 186.0 & 16 & 145.0 & 40 \\
\hline
\end{tabular}

repetitions for the determination of the LOD and LOQ. The LOD and the LOQ were statistically determined based on the $t_{99}^{S} L L M V$ method where $t_{99(\mathrm{n}-1)}=3$ (Corley 2003). The validity and precision of the method (analytical method efficiency) was determined with recovery tests. The recoveries were calculated based on the peak areas of the analytes, taking into account matrix and dilution effects (Butler et al. 2007; Corley 2003; Dankyi et al. 2015; González-Curbelo et al. 2011; Lesueur et al. 2008; Mekonen et al. 2014; Nguyen et al. 2008; Shrivastava and Gupta 2011). The linearity was determined by preparing a stock solution of pure standards of the pesticides studied and diluting them to produce a concentration range. The standard solution of the pesticides was run on LCMS/MS under the set of chromatographic conditions to produce 9 -point calibrations ranking from $0.0001 \mathrm{mg} / \mathrm{L}$ to $0.01 \mathrm{mg} / \mathrm{L}$. The recovery tests were done by spiking a mixture of 25 pesticides (Table 2) into blank samples of yam.
QuEChERS method and analyses of recovery and samples Pesticides residue determination in food commodities by the QuEChERS method is found to produce better recoveries compared with classical techniques of liquid-liquid extraction (Mekonen et al. 2014). The modified QuEChERS method, based on the procedure by the Association of Analytical Communities official method 2007.01 (Koesukwiwat et al. 2014; Mekonen et al. 2014; Neil et al. 2007) but without the cleanup phase was adopted for the extraction of the spiked samples and blank samples of yam. The cleanup phase was skipped because the yam tuber is a relatively clean product with low fat and pigment content (Udensi 2008; Kouassi et al. 1988; Muzac-Tucker et al. 1993; USDA, 2017). The QuEChERS method is found to give high-quality results for many pesticides (Wilkowska and Biziuk 2011). The procedure for spiking and extraction was executed in 9 distinct steps as presented in Table 4. 
Table 3 Chromatographic conditions of the LC-MS/MS system

\begin{tabular}{ll}
\hline HPLC Instrument & Waters ACQUITY UPLC \\
\hline Column & Waters HSS T3 (1.8 $\mu \mathrm{m})$ \\
Injection volume & $10 \mathrm{\mu L}$ \\
Oven temperature & $40{ }^{\circ} \mathrm{C}$ \\
Mobile phase A & Water $+10 \mathrm{mM}$ ammoniumacetate \\
Mobile phase B & Acetonitrile $+0.1 \%$ formic acid \\
Flow & $0.4 \mathrm{~mL} /$ min \\
Gradient & $0-0.25$ min 2\% solvent B \\
& $0-7$ min linear gradient to 98\% solvent B \\
& $7-8$ min 98\% solvent B \\
& $8-9$ min linear gradient to 2\% solvent \\
& $9-10$ min 2\% solvent B \\
Detector & Triple quadrupole mass spectrometer \\
Spectrometer & None \\
Interface & Electrospray ionisation \\
Potential & $5000 \mathrm{~V}$ \\
Temperature & $500{ }^{\circ} \mathrm{C}$ \\
Scan type & MRM (Multiple Reaction Monitoring Mode) \\
Collision gas & Argon \\
\hline
\end{tabular}

Sample extraction after preparation was done in accordance with the same QuEChERS procedure adopted for the recovery tests for the analytical method validation as described in Table 4 except for the spiking step. With a total of 180 samples from both Ghana and the Belgium markets, $10 \mathrm{~g}$ was weighed from each sample into a $50 \mathrm{~mL}$ tube using the Sartorius analytical balance. After the weighing step, steps 3 to 9 of the QuEChERS method (Table 4) were executed.

Table 4 Procedure for Spiking and Extraction

\begin{tabular}{|c|c|}
\hline Step & Description \\
\hline 1 & $\begin{array}{l}10 \mathrm{~g} \text { of blended yam samples were weighed in } 50 \mathrm{ml} \text { centrifuge } \\
\text { tubes on Sartorius analytical balance. }\end{array}$ \\
\hline 2 & $\begin{array}{l}\text { Blank samples were spiked with } 100 \mu \mathrm{L} \text { of mixed standard of the } \\
25 \text { compounds involved in } 8 \text { replicates. }\end{array}$ \\
\hline 3 & $\begin{array}{l}15 \mathrm{~mL} \text { of acetonitrile containing } 1 \% \text { glacial acetic acid }(\mathrm{v} / \mathrm{v}) \text { was } \\
\text { added in each sample by using a solvent dispenser. }\end{array}$ \\
\hline 4 & $\begin{array}{l}\text { Each tube was tightly cupped and shaken for } 1 \mathrm{~min} \text { to ensure } \\
\text { contact between the solvent and the sample matrix. }\end{array}$ \\
\hline 5 & $\begin{array}{l}6 \mathrm{~g} \text { anhydrous } \mathrm{MgSO} 4,1.5 \mathrm{~g} \mathrm{NaCL}, 1.5 \mathrm{~g} \text { sodium citrate tribasic } \\
\text { dihydrate }\left(\mathrm{C}_{6} \mathrm{H}_{2} \mathrm{Na}_{3} \mathrm{O}_{7} 2 \mathrm{H}_{2} \mathrm{O} \text { and } 0.75 \mathrm{~g} \text { sodium hydrogen citrate }\right. \\
\left(\mathrm{C}_{6} \mathrm{H}_{6} \mathrm{Na}_{2} \mathrm{O}_{7} 1.5 \mathrm{H}_{2} \mathrm{O}\right) \text { were added and the sample was shaken for } \\
5 \text { min on a mechanical shaker at } 300 \mathrm{rpm} \text { to enhance sample } \\
\text { throughput. }\end{array}$ \\
\hline 6 & The samples were centrifuged at 10,000 rpm for $5 \mathrm{~min}$. \\
\hline 7 & $5 \mathrm{~mL}$ aliquot of extract was taken into a $10 \mathrm{~mL}$ test tube. \\
\hline 8 & $\begin{array}{l}1 \mathrm{~mL} \text { of the aliquot of extract in the } 10 \mathrm{~mL} \text { tubes was taken } \\
\text { into } 10 \mathrm{~mL} \text { flask and diluted to } 10 \mathrm{~mL} \text { with water. }\end{array}$ \\
\hline 9 & $\begin{array}{l}1 \mathrm{~mL} \text { extract was then transferred from the } 10 \mathrm{~mL} \text { flask into } \\
\text { an auto sampler vial for LC-MS/MS analysis. }\end{array}$ \\
\hline
\end{tabular}

\section{Data analysis}

The pesticides residue data were analyzed using SPSS version 19. One sample t-test was conducted to determine the differences among the markets with regards to the number of pesticides detected and the number of samples contaminated per market.

\section{Results and discussion \\ Method validation results}

The QuEChERS method as adopted in this study was validated based on the performance criteria set out by the European Commission Directorate General for Health and Food Safety. These include sensitivity/linearity, percentage recoveries as a measure of trueness or bias, precision (relative standard deviation), LOD and LOQ. With regards to the method sensitivity/linearity, the calibration curves generated for the 25 pesticides were linear over a concentration range of $0.0001 \mathrm{mg} / \mathrm{kg}$

Table 5 Method validation results in Yam matrices: recovery \%, relative standard deviation, $L O D, L O Q$ and spiked concentration (0.0007 mg/kg)

\begin{tabular}{|c|c|c|c|c|}
\hline Pesticide & Recovery (\%) & RSD (\%) & LOD (mg/kg) & LOQ (mg/kg) \\
\hline Acetamiprid & 84 & 9 & 0.0005 & 0.0015 \\
\hline Azoxystrobin & 114 & 4 & 0.0003 & 0.0009 \\
\hline Bentazone & 95 & 15 & 0.0007 & 0.0020 \\
\hline Butachlor & 89 & 7 & 0.0004 & 0.0012 \\
\hline Cadusafos & 105 & 9 & 0.0005 & 0.0014 \\
\hline Carbendazim & 112 & 18 & 0.0007 & 0.0021 \\
\hline Carbofuran & 98 & 6 & 0.0002 & 0.0007 \\
\hline Chlorpyrifos & 90 & 12 & 0.0004 & 0.0011 \\
\hline Difenconazole & 94 & 6 & 0.0002 & 0.0007 \\
\hline Diuron & 79 & 18 & 0.0011 & 0.0032 \\
\hline Dimethoate & 104 & 20 & 0.0010 & 0.0030 \\
\hline Diazinon & 96 & 8 & 0.0004 & 0.0012 \\
\hline Epoxiconazole & 103 & 9 & 0.0010 & 0.0031 \\
\hline Fenpropimorph & 100 & 6 & 0.0002 & 0.0006 \\
\hline Imidacloprid & 74 & 13 & 0.0007 & 0.0022 \\
\hline Malathion & 101 & 7 & 0.0004 & 0.0013 \\
\hline Metalaxyl & 103 & 14 & 0.0009 & 0.0026 \\
\hline Pendimethalin & 107 & 12 & 0.0003 & 0.0009 \\
\hline Profenofos & 72 & 9 & 0.0004 & 0.0013 \\
\hline Propanil & 108 & 14 & 0.0005 & 0.0016 \\
\hline Propiconazole & 95 & 5 & 0.0002 & 0.0007 \\
\hline Propoxur & 95 & 7 & 0.0004 & 0.0012 \\
\hline Pyrachlostrobin & 99 & 7 & 0.0004 & 0.0011 \\
\hline Tryfloxystrobin & 105 & 5 & 0.0002 & 0.0007 \\
\hline Fenitrothion & 112 & 14 & 0.0025 & 0.0074 \\
\hline
\end{tabular}

$L O D$ limit of detection, $L O Q$ limit of quantification, $R S D$ relative standard deviation (\%) 
to $0.01 \mathrm{mg} / \mathrm{kg}$ and showed a correlation coefficient $\left(\mathrm{r}^{2}\right)$ of more than 0.9955 .

The method validation result is summarized in Table 5 . The recovery studies revealed that the QuEChERS method is an efficient method for multi-residue analysis of the tested pesticides in yam. The recoveries of all the 25 pesticides analyzed were well within the $70 \%-120 \%$ performance criteria (Bempah and Donkor 2011; Berrada et al. 2010; Gilbert-López et al. 2010; Lesueur et al. 2008; Lozowicka et al. 2015; Mekonen et al. 2014; Nguyen et al. 2008; Osman et al. 2010) These recoveries indicate that the method used is reproducible. In terms of accuracy and precision i.e. repeatability expressed in terms of relative standard deviation (RSD, \%), the 25 pesticides gave RSD varying between $4 \%$ and $20 \%$ at the spiking level.

With regards to the LOD and LOQ, the results revealed that the LOD for the 25 pesticides varied between $0.0002 \mathrm{mg} / \mathrm{kg}$ and $0.0025 \mathrm{mg} / \mathrm{kg}$ whereas the LOQ varied between $0.0006 \mathrm{mg} / \mathrm{kg}$ and $0.0074 \mathrm{mg} / \mathrm{kg}$. This is consistent with results of previous studies in which the LOD ranged between $0.0004 \mathrm{mg} / \mathrm{kg}$ and $0.048 \mathrm{mg} / \mathrm{kg}$ while LOQ ranged between $0.0012 \mathrm{mg} / \mathrm{kg}$ and $0.05 \mathrm{mg} /$ $\mathrm{kg}$ (Lesueur et al. 2008; Nguyen et al. 2008; Soler et al. 2005). The obtained LOD and LOQ for the tested pesticides, did fulfil the $10 \mu \mathrm{g} / \mathrm{kg}$ threshold required to monitor organic farming food (Lesueur et al. 2008). This result compares favourably with previous studies in which the LOD was as high as between $20 \mu \mathrm{g} / \mathrm{kg}$ and $115 \mu \mathrm{g} / \mathrm{kg}$ and LOQ was up to $400 \mu \mathrm{g} / \mathrm{kg}$ (Blasco et al. 2004, 2005, 2006; Soler et al. 2005; Zrostlíková et al. 2003).

\section{Pesticides residues in yam samples}

Following the validation exercise to determine the effectiveness and efficiency of the QuEChERS method for multi pesticides residue extraction from yam, the 180 yam samples were analyzed for 25 pesticides based on an initial screening of available pesticides on the Ghanaian market and in the updated pesticides register of Ghana. The analyzed pesticides included eleven insecticides (fenitrothion, propoxur, imidacloprid, malathion, profenofos, carbofuran, acetamiprid, dimethoate, cadusafos, diazinon and chlorpyrifos), nine fungicides (metalaxyl, fenpropimorph, pyrachlostrobin, propiconazole, tryfloxystrobin, carbendazim, azoxystrobin, difenconazole and epoxiconazole) and five herbicides (propanil, pendimethalin, diuron, bentazone and butachlor). Only 11 of the analyzed pesticides (Table 6) including four fungicides (metalaxyl, fenpropimorph, propiconazole and carbendazim), five insecticides (fenitrothion, cadusafos, imidacloprid, profenofos and propoxur) and two herbicides (bentazone and pendimethalin) were found in one or more than one of the yam samples.

Since interactions with players along the yam value chain from the farmer in the village through the
Ghanaian market to the shops in Ghent, Belgium, indicated that no post-harvest pesticide treatment is offered to yam for preserving it, these residues cannot be attributed to direct application of the pesticides to the yam tuber. However, since yam is cultivated in a mixed cropping system and rotated with other crops in Ghana, there seems to be an important way through which these compounds could contaminate the yam. This could be on-farm contamination through foliar uptake due to spray drift or root uptake due to crop rotation, depending on the environmental fate of the pesticides involved (EXTOXNET, 1993.; Nemeth-Konda et al. 2002; Wu et al. 2002; Yule and Duffy 1972; Zheng et al. 1994). The detected pesticides, except for fenitrothion, profenofos and bentazone which are reported to degrade rapidly in the soil, have moderate to high persistence in the soil (University of Hertfordshire, PPDB). Their DT50s in soil (Table 7) vary from 2.7 days up to 191 days. Among these pesticides, benazone, metalaxyl, propoxur and imidacloprid have a high solubility $(7112 \mathrm{mg} / \mathrm{L}, 8400 \mathrm{mg} / \mathrm{L}$, $1800 \mathrm{mg} / \mathrm{L}$ and $610 \mathrm{mg} / \mathrm{L}$ respectively) while profenofos, fenitrothion, pendimethalin, carbendazim and fenpropimorph have a low solubility $(28 \mathrm{mg} / \mathrm{L}, 19 \mathrm{mg} / \mathrm{L}$, $0.33 \mathrm{mg} / \mathrm{L}, 8 \mathrm{mg} / \mathrm{L}$ and $4.32 \mathrm{mg} / \mathrm{L}$ respectively). Cadusafos and propiconazole have a moderate solubility of $245 \mathrm{mg} / \mathrm{L}$ and $150 \mathrm{mg} / \mathrm{L}$ respectively. With regards to volatility, cadusafos is the only pesticide among the detected pesticides with high a volatility $(119.6 \mathrm{mPa})$ while the others have a low volatility ranging between $4.0 \times$ $10-07 \mathrm{mPa}$ and $3.9 \mathrm{mPa}$ (University of Hertfordshire, PPDB). Under optimum soil conditions, pesticides with a higher DT50 and a moderate to a high solubility, have the tendency to be absorbed by roots of crops growing in the field and subsequent crops in crop rotations (Doan Ngoc et al. 2015; Hwang et al. 2015; Kucharski et al. 2012). Pesticides with high volatility can be absorbed by the foliar of non-target crops through spray drift and can also be taken up by crop roots under dry soil conditions. One other possible way by which the contamination could arise is through contaminated surfaces due to storage and distribution practices (Ecobichon 2001; Gerken et al. 2001; Hassink et al. 2007). The concentration of the pesticides and the respective MRLs are presented in Table 6 . The results show that about $46 \%$ of the yam samples contained one or more than one of the eleven detected pesticides. Among the 11 pesticides fenpropimorph was the most frequently detected pesticide, occurring in 179 out of the 180 samples. This was followed by cadusafos and fenitrothion occurring in 171 and 126 samples respectively. Next to these, propiconazole, metalaxyl, propoxur, bentazone and carbendazim, occurred in 38, 29, 19, 6 and 2 samples respectively. The rest, including imidacloprid, pendimethalin and profenofos, occurred in only 1 sample each. These results are 
Table 6 Detected Pesticides in Analyzed Yam Samples Across Ghanaian and Belgian Markets

\begin{tabular}{|c|c|c|c|c|c|c|c|}
\hline Pesticides & No of samples/30 & EU MRL (mg/kg) & $\operatorname{Min}(\mathrm{mg} / \mathrm{kg})$ & Average (mg/kg) & Median & 95th percentile & $\operatorname{Max}(\mathrm{mg} / \mathrm{kg})$ \\
\hline \multicolumn{8}{|c|}{ Accra Market, Ghana } \\
\hline metalxyl & $1 / 30$ & $0.05^{*}$ & $0.0003^{* *}$ & $0.0003^{* *}$ & $0.0003^{* *}$ & $0.0003^{* *}$ & $0.0003^{* *}$ \\
\hline fenpropimorph & $30 / 30$ & $0.01^{*}$ & 0.00001 & 0.0001 & 0.00011 & 0.0002 & 0.003 \\
\hline propiconazole & $4 / 30$ & $0.01^{*}$ & $0.0003^{* *}$ & $0.0003^{* *}$ & $0.0003^{* *}$ & $0.0003^{* *}$ & $0.0003^{* *}$ \\
\hline cadusafos & $30 / 30$ & $0.01^{*}$ & 0.00001 & 0.00014 & 0.00015 & 0.00019 & 0.0002 \\
\hline fenitrothion & $10 / 30$ & $0.01^{*}$ & 0.0003 & 0.0022 & 0.0016 & 0.0053 & 0.0065 \\
\hline \multicolumn{8}{|c|}{ Kintampo Market, Ghana } \\
\hline propoxur & $6 / 30$ & $0.05^{*}$ & 0.00002 & 0.00003 & 0.00003 & 0.00004 & 0.00004 \\
\hline metalaxyl & $3 / 30$ & $0.05^{*}$ & $0.0003^{* *}$ & $0.0003^{* *}$ & $0.0003^{* *}$ & $0.0003^{* *}$ & $0.0003^{* *}$ \\
\hline fenpropimorph & $30 / 30$ & $0.01^{*}$ & 0.00003 & 0.00018 & 0.00014 & 0.00043 & 0.00081 \\
\hline propiconazole & $9 / 30$ & $0.01^{*}$ & 0.00001 & 0.000018 & 0.00002 & 0.00003 & 0.00004 \\
\hline bentazone & $1 / 30$ & $0.03^{*}$ & $0.0002^{* *}$ & $0.0002^{* *}$ & $0.0002^{* *}$ & $0.0002^{* *}$ & $0.0002^{* *}$ \\
\hline cadusafos & $30 / 30$ & $0.01^{*}$ & 0.00006 & 0.0001 & 0.00015 & 0.000095 & 0.00019 \\
\hline profenofos & $1 / 30$ & $0.01^{*}$ & $0.0005^{* *}$ & $0.0005^{* *}$ & $0.0005^{* *}$ & $0.0005^{* *}$ & $0.0005^{* *}$ \\
\hline fenitrothion & $14 / 30$ & $0.01^{*}$ & 0.0003 & 0.0086 & 0.0087 & 0.0015 & 0.0016 \\
\hline \multicolumn{8}{|c|}{ Kumasi Market, Ghana } \\
\hline propoxur & $4 / 30$ & $0.05^{*}$ & $0.0001^{* *}$ & $0.0001^{* *}$ & $0.0001^{* *}$ & $0.0001^{* *}$ & $0.0001^{* *}$ \\
\hline metalaxyl & $9 / 30$ & $0.05^{*}$ & 0.00001 & 0.00002 & 0.00001 & 0.00007 & 0.0001 \\
\hline fenpropimorph & $30 / 30$ & $0.01^{*}$ & 0.00004 & 0.00017 & 0.00011 & 0.00055 & 0.0006 \\
\hline propiconazole & $8 / 30$ & $0.01^{*}$ & $0.0003^{* *}$ & $0.0003^{* *}$ & $0.0003^{* *}$ & $0.0003^{* *}$ & $0.0003^{* *}$ \\
\hline bentazone & $4 / 30$ & $0.03^{*}$ & 0.00031 & 0.00083 & 0.0008 & 0.00014 & 0.00144 \\
\hline cadusafos & $30 / 30$ & $0.01^{*}$ & 0.00003 & 0.000072 & 0.00007 & 0.00011 & 0.00012 \\
\hline imidacloprid & $1 / 30$ & 0.5 & $0.0004^{* *}$ & $0.0004^{* *}$ & $0.0004^{* *}$ & $0.0004^{* *}$ & $0.0004^{* *}$ \\
\hline fenitrothion & 29 & $0.01^{*}$ & 0.0001 & 0.0019 & 0.0012 & 0.0062 & 0.0092 \\
\hline pendimethalin & $1 / 30$ & $0.05^{*}$ & $0.0003^{* *}$ & $0.0003^{* *}$ & $0.0003^{* *}$ & $0.0003^{* *}$ & $0.0003^{* *}$ \\
\hline \multicolumn{8}{|c|}{ Takoradi Market, Ghana } \\
\hline propoxur & $2 / 30$ & $0.05^{*}$ & $0.0001^{* *}$ & $0.0001^{* *}$ & $0.0001^{* *}$ & $0.0001^{* *}$ & $0.0001^{* *}$ \\
\hline metalaxyl & $2 / 30$ & $0.05^{*}$ & $0.0003^{* *}$ & $0.0003^{* *}$ & $0.0003^{* *}$ & $0.0003^{* *}$ & $0.0003^{* *}$ \\
\hline fenpropimorph & $30 / 30$ & $0.01^{*}$ & 0.00003 & 0.00012 & 0.0001 & 0.0003 & 0.0004 \\
\hline propiconazole & $1 / 30$ & $0.01^{*}$ & $0.0003^{* *}$ & $0.0003^{* *}$ & $0.0003^{* *}$ & $0.0003^{* *}$ & $0.0003^{* *}$ \\
\hline cadusafos & $24 / 30$ & $0.01^{*}$ & 0.00003 & 0.00012 & 0.0001 & 0.0003 & 0.0004 \\
\hline fenitrothion & $15 / 30$ & $0.01^{*}$ & 0.0008 & 0.0034 & 0.0025 & 0.0096 & 0.0111 \\
\hline \multicolumn{8}{|c|}{ Tamale Market, Ghana } \\
\hline metalaxyl & $7 / 30$ & $0.05^{*}$ & $0.0003^{* *}$ & $0.0003^{* *}$ & $0.0003^{* *}$ & $0.0003^{* *}$ & $0.0003^{* *}$ \\
\hline fenpropimorph & $29 / 30$ & $0.01^{*}$ & 0.00001 & 0.00008 & 0.00004 & 0.00027 & 0.00041 \\
\hline propiconazole & $3 / 30$ & $0.01^{*}$ & $0.0003^{* *}$ & $0.0003^{* *}$ & $0.0003^{* *}$ & $0.0003^{* *}$ & $0.0003^{* *}$ \\
\hline carbendazim & $1 / 30$ & $0.1^{*}$ & $0.0004^{* *}$ & $0.0004^{* *}$ & $0.0004^{* *}$ & $0.0004^{* *}$ & $0.0004^{* *}$ \\
\hline bentazone & $1 / 30$ & $0.03^{*}$ & $0.0002^{* *}$ & $0.0002^{* *}$ & $0.0002^{* *}$ & $0.0002^{* *}$ & $0.0002^{* *}$ \\
\hline cadusafos & $27 / 30$ & $0.01^{*}$ & 0.00005 & 0.000102 & 0.00009 & 0.00018 & 0.00019 \\
\hline fenitrothion & $28 / 30$ & $0.01^{*}$ & 0.0002 & 0.0025 & 0.0013 & 0.0068 & 0.0085 \\
\hline \multicolumn{8}{|c|}{ Ghent Market, Belgium } \\
\hline propoxur & $7 / 30$ & $0.05^{*}$ & 0.00003 & 0.00004 & 0.0005 & 0.00006 & 0.00007 \\
\hline metalxyl & $7 / 30$ & $0.05^{*}$ & $0.0003^{* *}$ & $0.0003^{* *}$ & $0.0003^{* *}$ & $0.0003^{* *}$ & $0.0003^{* *}$ \\
\hline fenpropimorph & $30 / 30$ & $0.01^{*}$ & 0.00005 & 0.00013 & 0.00013 & 0.00024 & 0.00033 \\
\hline
\end{tabular}


Table 6 Detected Pesticides in Analyzed Yam Samples Across Ghanaian and Belgian Markets (Continued)

\begin{tabular}{llllllll}
\hline Pesticides & No of samples/30 & EU MRL $(\mathrm{mg} / \mathrm{kg})$ & Min $(\mathrm{mg} / \mathrm{kg})$ & Average $(\mathrm{mg} / \mathrm{kg})$ & Median & 95 th percentile & Max $(\mathrm{mg} / \mathrm{kg})$ \\
\hline propiconazole & $13 / 30$ & $0.01^{*}$ & 0.0001 & 0.000014 & 0.00001 & 0.00002 & 0.00002 \\
carbendazim & $1 / 30$ & $0.1^{*}$ & $0.0004^{* *}$ & $0.0004^{* *}$ & $0.0004^{* *}$ & $0.0004^{* *}$ & $0.0004^{* *}$ \\
cadusafos & $30 / 30$ & $0.01^{*}$ & 0.00005 & 0.00009 & 0.000085 & 0.00012 & 0.00014 \\
fenitrothion & $30 / 30$ & $0.01^{*}$ & 0.0009 & 0.0039 & 0.0032 & 0.0099 & 0.0146 \\
\hline
\end{tabular}

MRL Maximum Residue Limit

$* *=L O D$ value from validation

* = EU MRL default value

consistent with previous studies in Ghana in which residues of propoxur and carbendazim were detected in crop produce at levels below the EU MRLs (Aboagye and E. 2002; Apau and Dodoo 2011; Samuel et al., 2012). Among the markets from which the yam samples were obtained, the market at Accra recorded the least number of pesticides found with only 5 pesticides, followed by Takoradi with 6 pesticides. The Tamale and Ghent markets recorded 7 pesticides each, while Kintampo and the Kumasi markets recorded 8 and 9 pesticides respectively. There was significant difference $(P<0.05)$ among the markets with regards to the number of samples contaminated by the pesticides. The Takoradi and Kintampo markets had the least number of samples contaminated (12 samples respectively). These were followed by the Kumasi, Tamale and Accra markets with 13, 14 and 15 samples respectively contaminated. The market in Ghent had the highest number of samples contaminated (17).

With regards to the concentration of the detected pesticides across the sample markets, there was significant difference $(P<0.05)$ among the markets. The differences notwithstanding, it was observed that the residues of the detected pesticides were very low. The concentration of each of the pesticides except fenitrothion was lower than $0.01 \mathrm{mg} / \mathrm{kg}$. These levels of residues indicate contamination

Table 7 Properties of Detected Pesticides

\begin{tabular}{llll}
\hline Pesticide & DT50 Soil (days) & Solubility $(\mathrm{mg} / \mathrm{L})$ & Volatility $(\mathrm{mPa})$ \\
\hline bentazone & 20 & 7112 & 0.017 \\
carbendazim & 40 & 8 & 0.098 \\
cadusafos & 38 & 245 & 119.6 \\
fenitrothion & 2.7 & 19 & 0.67 \\
fenpropimorph & 35 & 4.32 & 3.94 \\
imidacloprid & 174 & 610 & $4.0 \times 10^{-07}$ \\
metalaxyl & 36 & 8400 & 0.75 \\
pendimethalin & 182 & 0.33 & 3.34 \\
profenofos & 7 & 28 & 1.53 \\
propiconazole & 72 & 150 & 0.056 \\
Propoxur & 79 & 1800 & 1.3
\end{tabular}

DT50 Half-life of pesticides in soil of the yam tubers through other sources other than treatment by pesticides.

When compared with the EU MRL as provided by the European Commission, all the detected pesticides had their concentrations far below their respective MRL for yam. The MRLs as reported in Table 6, except for imidacloprid, are default values. This means that no study was conducted for them in yam hence the authorities decided to use default values of $0.01 \mathrm{mg} / \mathrm{kg}$ and $0.05 \mathrm{mg} /$ $\mathrm{kg}$ as their default MRLs. This is consistent with previous studies in which pesticides were detected in a whole food basket including yam at concentrations below the MRLs (Adeyeye and Osibanjo 1999; Asiedu 2013; Bempah and Donkor 2011; Kolani et al. 2016; Yang et al. 2016). Other studies show similar results (Blasco et al. 2006; Lozowicka et al. 2015; Osibanjo and Adeyeye 1995; $\mathrm{Su}$ et al. 2003).

Besides the EU Commission MRL, the Codex Alimentarius MRL was another international food safety standard limits that the residues as observed in this study were supposed to be compared with. Unfortunately, at the time of the study there was no MRL for yam on the Codex Alimentarius maximum residue limit database.

\section{Conclusion}

The modified QuEChERS method has proved to be effective for the analysis of pesticides residues in yam. Eleven out of 25 pesticides monitored were detected in about $46 \%$ of the yam samples collected from Ghana and Belgium markets. Samples showed contamination of one or more of the eleven different pesticides. However, none of the pesticides detected in the yam samples exceeded the MRL set for yam by the European Commission Directorate General for Health and Food Safety. For now, the Ghana yam can be regarded as wholesome food commodity which may not pose any threat to human health. There were no codex alimentarius MRL values for yam. Hence, we recommend that codex alimentarius should establish maximum residue limits for yam. We also recommend that the government should provide enough resources to the regulatory authorities to do effective monitoring to ensure that pesticides are handled according to industry best practices. Specifically, education programmes on how to 
avoid storage contamination and drift issues in mixed cropping systems should be instituted.

\section{Abbreviations}

CE: Collision Energy; CV: Cone Voltage; ESI: Electron Spay lonization; EU: European Union; eV: Electric Volt; GETfund: Ghana Education Trust Fund; HPLC: High Performance Liquid Chromatography; LC-MS/MS: Liquid Chromatography Tandem Mass Spectrometry; MRL: Maximum Residue Limit; QuEChERS: Quick, Easy, Cheap, Efficient, Rugged and Safe; UPLC: Ultra Performance Liquid Chromatography

\section{Acknowledgements}

The Authors wish to thank the Ghana Education Trust Fund (GETfund) for paying the bench fee for the study. The Authors will also like to thank Lilian Goeteyn for her support in the laboratory.

\section{Funding}

The Ghana education GETfund has provided funding for the laboratory work and the authors have individually contributed for the publication.

\section{Availability of data and materials}

The data supporting our findings have been attached as Additional files.

\section{Authors' contributions}

Each of the authors made a significant contribution to the research. The corresponding author (Abukari Wumbei) has been involved from sample collection through sample preparation, extraction, drafting of the manuscript to the submission of the manuscript. David Senaeve and Michael Houbraken handled the analysis of the samples and contributed to the drafting of the manuscript. Pieter Spanoghe as the promoter of the research, provided the overall direction and guidance to the team right from the conception of the research to the submission of the manuscript. All authors read and approved the final manuscript.

\section{Ethics approval and consent to participate}

Not applicable.

\section{Consent for publication}

Not applicable.

\section{Competing interests}

We declare that none of us, the authors have any competing interests as far as the submission of this paper is concerned.

\section{Received: 28 November 2017 Accepted: 20 February 2018} Published online: 01 March 2018

\section{References}

Aboagye, E., \& E. Patterns of Pesticide Use and Residue Levels in Exportable Pineapple (Ananas Comosus L. Merr.). (2002) Retrieved from http://ugspace. ug.edu.gh/handle/123456789/7339

Adeyeye, A., \& Osibanjo, O.. Residues of organochlorine pesticides in fruits, vegetables and tubers from Nigerian markets. Sci Total Environ, (1999) 231(2-3), 227-233. https://doi.org/10.1016/S0048-9697(99)00067-4

Anaadumba P. Analysis of incentives and disincentives for yam in Ghana (2013).

Apau J, Dodoo D. Lindane and propoxur residues in cocoa from central region of Ghana. J Sci Technol (Ghana). 2011;30(3) https://doi.org/10.4314/just.v30i3.64624.

Asiedu, E. Pesticide contamination of fruits and vegetables: a market-basket survey from selected regions in Ghana,(2013) (June), 1-145.

Bempah CK, Donkor AK. Pesticide residues in fruits at the market level in Accra metropolis, Ghana, a preliminary study. Environ Monit Assess. 2011;175(1-4): 551-61. https://doi.org/10.1007/s10661-010-1550-0.

Berrada H, Fernández M, Ruiz MJ, Moltó JC, Mañes J, Font G. Surveillance of pesticide residues in fruits from Valencia during twenty months (2004/05). Food Control. 2010;21(1):36-44. https://doi.org/10.1016/j.foodcont.2009.03 011.

Blasco C, Font G, Picó Y. Multiple-stage mass spectrometric analysis of six pesticides in oranges by liquid chromatography-atmospheric pressure chemical ionization-ion trap mass spectrometry. J Chromatogr I. 2004; 1043(2):231-8. Retrieved from http://www.ncbi.nlm.nih.gov/pubmed/ 15330097
Blasco C, Font G, Picó Y. Analysis of pesticides in fruits by pressurized liquid extraction and liquid chromatography-ion trap-triple stage mass spectrometry. J Chromatogr A. 2005;1098(1-2):37-43. https://doi.org/10.1016/ j.chroma.2005.08.037.

Blasco C, Font G, Y. P. Evaluation of 10 pesticide residues in oranges and tangerines from Valencia (Spain). Food Control. 2006;17(11):841-6. Retrieved from http://www.sciencedirect.com/science/article/pii/S0956713505001362

Bodirsky BL, Rolinski S, Biewald A, Weindl I, Popp A, Lotze-Campen H. Global food demand scenarios for the 21st century. PLoS One. 2015;10(11):e0139201. https://doi.org/10.1371/journal.pone.0139201.

Butler, J., Steiniger, D., Phillips, E., \& Scientific, T. F. Analysis of pesticide residues in lettuce using a modified QuEChERS extraction technique and single Quadrupole GC / MS (2007).

Cha ES, Hwang S, Lee WJ. Childhood leukemia mortality and farming exposure in South Korea: a national population-based birth cohort study. Cancer Epidemiol. 2014;38(4):401-7. https://doi.org/10.1016/j.canep.2014.05.003.

Corley, J. Best practices in establishing detection and quantification limits for pesticide residues in foods. Handbook of Residue Analytical Methods for Agrochemicals, (2003) 409(c), 1-18.

Dankyi E, Carboo D, Gordon C, Fomsgaard IS. Application of the QuEChERS procedure and LC-MS/MS for the assessment of neonicotinoid insecticide residues in cocoa beans and shells. J Food Compos Anal. 2015;44:149-57. https://doi.org/10.1016/j.jfca.2015.09.002.

Doan Ngoc K, van den Berg F, Houbraken M, Spanoghe P. Volatilisation of pesticides after application in vegetable greenhouses. Sci Total Environ. 2015; 505:670-9. https://doi.org/10.1016/j.scitotenv.2014.10.036.

Ecobichon DJ. Pesticide use in developing countries. Toxicology. 2001;160(1):27-33. https://doi.org/10.1016/50300-483X(00)00452-2.

EXTOXNET. A Pesticide Information Project of Cooperative Extension Offices of Cornell University, Michigan State University, Oregon State University, and University of California at Davis. Major support and funding was provided by the USDA/Extension Service/National Agricultural Pesticide Impact Assessment Program. Propoxur. 1993. Retrieved from http://pmep.cce.cornell. edu/profiles/extoxnet/metiram-propoxur/propoxur-ext.html

Frimpong SK, Philip O, Yeboah b, John J, Fletcher J, P., b, d, \& and Dickson. Multiresidue levels of Organophosphorus pesticides in cocoa beans from Ghana. Elixir Food Science. 2012;47:8721-5. Retrieved from http://www. elixirpublishers.com/articles/1362029158 47(2012)8721-8725.pdf

Gerken A, Suglo J, Braun M. Pesticides use and policies in Ghana an economic and institutional analysis of current practice and factors influencing pesticide use. Policy. 2001;10

Gilbert-López B, García-Reyes JF, Mezcua M, Ramos-Martos N, Fernández-Alba AR, Molina-Díaz A. Multi-residue determination of pesticides in fruit-based soft drinks by fast liquid chromatography time-of-flight mass spectrometry. Talanta. 2010;81(4-5):1310-21. https://doi.org/10.1016/j.talanta.2010.02.026.

González-Curbelo MÁ, Hernández-Borges J, Ravelo-Pérez LM, Rodríguez-Delgado MÁ. Insecticides extraction from banana leaves using a modified QuEChERS method. Food Chem. 2011;125(3):1083-90. https://doi.org/10.1016/ffoodchem.2010.09.083.

Hassink J, Platz K, Stadler R, Zangmeister W, Fent G, Möndel M, Kubiak R. Comparison of wind tunnel and field experiments to measure potential deposition of fenpropimorph following volatilisation from treated crops. Pest Manag Sci. 2007;63(2):171-9. https://doi.org/10.1002/ps.1317.

Hwang JI, Lee SE, Kim JE. Plant uptake and distribution of endosulfan and its sulfate metabolite persisted in soil. PLoS One. 2015;10(11):1-12. https://doi. org/10.1371/journal.pone.0141728

Koesukwiwat U, Sanguankaew K, Leepipatpiboon N. Evaluation of a modified QuEChERS method for analysis of mycotoxins in rice. Food Chem. 2014;153: 44-51. https://doi.org/10.1016/j.foodchem.2013.12.029.

Kolani L, Mawussi G, Sanda K. Assessment of Organochlorine pesticide residues in vegetable samples from some agricultural areas in Togo. Am J Anal Chem. 2016;7(7):332-41. https://doi.org/10.4236/ajac.2016.74031.

Kouassi B, Diopoh J, Leroy Y, Fournet B. Total amino acids and fatty acids composition of yam (Dioscorea) tubers and their evolution during storage. J Sci Food Agric. 1988;42(3):273-85. https://doi.org/10.1002/jsfa.2740420310.

Kucharski M, Sadowski J, Domaradzki K. Degradation rate of Chloridazon in soil as influenced by adjuvants. Journal of Plant Protection Research. 2012;52(1): 2010-3. https://doi.org/10.2478/v10045-012-0018-3.

Lesueur C, Knittl P, Gartner M, Mentler A, Fuerhacker M. Analysis of 140 pesticides from conventional farming foodstuff samples after extraction with the modified QuECheRS method. Food Control. 2008;19(9):906-14. https://doi. org/10.1016/j.foodcont.2007.09.002. 
Lozowicka B, Abzeitova E, Sagitov A, Kaczynski P, Toleubayev K, Li A. Studies of pesticide residues in tomatoes and cucumbers from Kazakhstan and the associated health risks. Environ Monit Assess. 2015;187(10):609. https://doi. org/10.1007/s10661-015-4818-6.

Mekonen S, Ambelu A, Spanoghe P. Pesticide residue evaluation in major staple food items of Ethiopia using the QuEChERS method: a case study from the jimma zone. Environ Toxicol Chem. 2014;33(6):1294-302. https:/doi.org/10.1002/etc.2554.

Muzac-Tucker I, Asemota HN, Ahmad MH. Biochemical composition and storage of Jamaican yams (Dioscorea sp). J Sci Food Agric. 1993;62(3):219-24. https:// doi.org/10.1002/jsfa.2740620303.

Neil, C. M. O., Tully, J., García, A. V., Contreras, M., Mol, H., Heinke, V., ... Parker, A. (2007). Determination of pesticide residues in foods by acetonitrile extraction and partitioning with magnesium sulfate: collaborative study, 485-520.

Nemeth-Konda L, Füleky G, Morovjan G, Csokan P. Sorption behaviour of acetochlor, atrazine, carbendazim, diazinon, imidacloprid and isoproturon on Hungarian agricultural soil. 2002; https://doi.org/10.1016/50045-6535(02)00106-6.

Nguyen TD, Han EM, Seo MS, Kim SR, Yun MY, Lee DM, Lee GH. A multi-residue method for the determination of 203 pesticides in rice paddies using gas chromatography/mass spectrometry. Anal Chim Acta. 2008;619(1):67-74. https://doi.org/10.1016/j.aca.2008.03.031.

Ntow WJ, Tagoe LM, Drechsel P, Kelderman P, Nyarko E, Gijzen HJ. Occupationa exposure to pesticides: blood cholinesterase activity in a farming community in Ghana. Arch Environ Contam Toxicol. 2009;56(3):623-30. https://doi.org/10. 1007/s00244-007-9077-2.

Osibanjo O, Adeyeye A. Organochlorine pesticide residues in cereals in Nigerian markets. Bulletin of Environmental Contamination \& Toxicology. 2015;54(3): 460. Retrieved from http://connection.ebscohost.com/c/articles/70790999/ organochlorine-pesticide-residues-cereals-nigerian-markets.

Osman KA, Al-Humaid AM, Al-Rehiayani SM, Al-Redhaiman KN. Monitoring of pesticide residues in vegetables marketed in Al-Qassim region, Saudi Arabia. Ecotoxicol Environ Saf. 2010;73(6):1433-9. https://doi.org/10.1016/j.ecoenv.2010.05.020.

Shrivastava A, Gupta V. Methods for the determination of limit of detection and limit of quantitation of the analytical methods. Chronicles of Young Scientists. 2011;2(1):21. https://doi.org/10.4103/2229-5186.79345.

Soler C, Mañes J, Picó Y. Comparison of liquid chromatography using triple quadrupole and quadrupole ion trap mass analyzers to determine pesticide residues in oranges. Journal of Chromatography. A, 2005;1067(1-2):115-125 Retrieved from http://www.ncbi.n/m.nih.gov/pubmed/15844516.

Su Y, Mitchell SH, Mac AntSaoir S. Carbendazim and metalaxyl residues in postharvest treated apples. Food Addit Contam. 2003;20(8):720-7. https:/doi.org/ 10.1080/0265203031000138268.

Udensi, E. A. (Department of Food Science and Technology, Abia State University, N. (2008). Chemical Composition of.

University of Hertfordshire. Pesticides Properties Data Base (PPDB). General Information formetalaxyl - M. 2017. Retrieved May 16, 2017, from http:// sitem.herts.ac.uk/aeru/ppdb/en/Reports/445.htm

USDA. National Nutrient Database for Standard Reference Release 28. Basic Report 11601, Raw Yam. Retrieved January 13, 2017, from https://ndb.nal.usda. $\mathrm{gov} / \mathrm{ndb} / \mathrm{foods} / \mathrm{show} / 3266$ ? manu=\&fgcd=\&ds=StandardReference.

Wilkowska A, Biziuk M. Determination of pesticide residues in food matrices using the QuEChERS methodology. Food Chem. 2011;125(3):803-12. https:// doi.org/10.1016/j.foodchem.2010.09.094.

Wu L, Liu G, Yates M, Green R, Pacheco P, Gan J, Yates S. Environmental fate of metalaxyl and chlorothalonil applied to a bentgrass putting green under southern California climatic conditions. Pest Manag Sci. 2002;58(4):335-42. https://doi.org/10.1002/ps.461.

Yang X, Luo J, Li S, Liu C. Evaluation of nine pesticide residues in three minor tropical fruits from southern China. Food Control. 2016;60:677-82. https://doi. org/10.1016/j.foodcont.2015.08.036.

Yule WN, Duffy JR. The persistence and fate of fenitrothion insecticide in a forest environment. Bull Environ Contam Toxicol. 1972;8(1):10-8. https://doi.org/10. 1007/BF01684498

Zheng SQ, Cooper JF, Palcy L, Coste CM, Marnotte P. Mobility and dissipation of cadusafos in banana fields in Martinique. Sci Total Environ. 1994;156:1-9. Retrieved from http://ac.els-cdn.com/0048969794904154/1-s2.00048969794904154-main.pdf? tid=222743fa-1dd1-11e7-8f2700000aabof27\&acdnat=1491817152_5d4c9b95c0d8707a2da2324e026c3cb0

Zrostlíková J, Hajšlová J, Kovalczuk Poustka J. Determination of Seventeen Polar/ Thermolabile Pesticides in Apples and Apricots by Liquid Chromatography/ Mass Spectrometry. 2003. Retrieved from http://lib3.dss.go.th/fulltext/Journal/J. AOAC1999-2003/J.AOAC2003/v86n3(may-jun)/v86n3p612.pdf.

\section{Submit your manuscript to a SpringerOpen ${ }^{\circ}$ journal and benefit from:}

- Convenient online submission

- Rigorous peer review

- Open access: articles freely available online

- High visibility within the field

- Retaining the copyright to your article

Submit your next manuscript at $\boldsymbol{\nabla}$ springeropen.com 